\title{
Predicting Diameter Increase Using a Quadriceps Tendon Augmentation for Undersized Hamstring Grafts in ACL Reconstruction
}

\section{Yoan Bourgeault-Gagnon}

Université de Sherbrooke: Universite de Sherbrooke

Keith Alexandre Leang

Université de Sherbrooke: Universite de Sherbrooke

Frédéric Balg

Université de Sherbrooke: Universite de Sherbrooke

Sonia Bédard ( $\square$ sonia.bedard2@usherbrooke.ca )

Centre intégré universitaire de santé et de services sociaux de l'Estrie - Centre hospitalier universitaire de

Sherbrooke https://orcid.org/0000-0002-8100-5908

\section{Karina Lebel}

Université de Sherbrooke: Universite de Sherbrooke

\section{François Vézina}

Université de Sherbrooke: Universite de Sherbrooke https://orcid.org/0000-0002-9661-241X

\section{Research Article}

Keywords: quadriceps, tendon, $A C L$, reconstruction

Posted Date: December 29th, 2021

DOI: https://doi.org/10.21203/rs.3.rs-1164210/v1

License: (c) (i) This work is licensed under a Creative Commons Attribution 4.0 International License.

Read Full License 


\section{Abstract}

Background The failure rate for ACL reconstruction varies between 5 to $25 \%$ depending on the population. Recent studies found a higher failure rate with grafts of 8 millimeters in diameter or less. Various options are described when the graft's diameter is inferior to the target value, but little literature helps us predict the final diameter during surgeries. Therefore, this study's goal is to describe a new technique supplementing a hamstring graft folded in half with a quadricipital tendon band of partial width and thickness $(4 S+Q)$, and to predict the final diameter.

Methods Thirty-three cadaveric knees were dissected in order to harvest semitendinosus and gracilis tendons (4S) along with a $6 \mathrm{~mm}$ wide tendon band from the rectus femoris. Harvesting was done according to the usual surgical technique. Measures of length and diameter in $4 S$ and $4 S+Q$ configurations were performed separately by three evaluators.

Results The threshold diameter of $8,5 \mathrm{~mm}$ was attained in only $30 \%$ of $4 \mathrm{~S}$ grafts within our population in comparison with $88 \%$ when augmented with a quadriceps band. The average diameter increase with the $4 S+Q$ configuration was $1,49 \mathrm{~mm}$. A threshold of $7,5 \mathrm{~mm}$ was established for the applicability of this augmentation technique considering that $93 \%$ of the grafts measuring $7,5 \mathrm{~mm}$ or more reached the $8,5 \mathrm{~mm}$ target.

Conclusions The $4 S+Q$ configuration offers a salvage option worth adding to one's arsenal, significantly increasing the graft's diameter. The width of the quadricipital tendon sample can be adjusted and will need further study.

\section{Introduction}

Despite several advances in surgical techniques, the failure rate of anterior cruciate ligament reconstruction generally varies between 5 and 25\%[1]. Principal factors influencing these results are the definition of failure, the patient's age, the surgical techniques employed, the level of physical activity and the size of grafts[1][2][3][4][5][6][7][8].

The usual reconstruction practice in our center is the autograft of doubled semitendinosus and gracilis (4S) [9][10]. Biomechanical studies show an inversely proportional relationship between the graft's size and the risk of rerupture[11]. A large-scale clinical study relates a reduction in relative risk of almost $15 \%$ per $0,5 \mathrm{~mm}$ increase in graft diameter[12][13]. These results are in agreement with those of other researchers who found a higher failure rate[1][3][4][14] and lesser functional results[4] with grafts measuring $8 \mathrm{~mm}$ in diameter or less.

Different options can be considered when the harvested graft's diameter is inferior to the target value. The most frequently used, due to its simplicity and the fact that it doesn't increase morbidity, is to triple the graft in order to obtain 5 or 6 strands (5S or $6 S$ )[15][16]. Although in some situations, length could be 
unsatisfactory after tripling the graft or the graft could, even tripled, maintain a smaller diameter than desired and that another supplementation technique must be utilized.

The option of a hybrid allograft/autograft is associated with a higher failure rate and a lesser integration than a 4S graft of the same diameter[17][18][19]. In this context, we began to consider utilizing a partial width quadricipital tendon band (rectus femoris only) as supplementation of a tibial hamstring autograft with a diameter deemed unsatisfactory. The harvesting of quadricipital tendons in ACL reconstruction is well-established and globally accepted as a principal graft[20][21][22][23][24][25][26][27][28][29]. However, Wilson et al. are currently the only authors having described and tested the biomechanical characteristics of utilizing quadricipital tendons (Q) as supplementation of a 4S graft[30]. The advantage of this technique relies on the ability to maintain the full length of the $4 \mathrm{~S}$ graft. Only an additional $3 \mathrm{~cm}$ incision is needed to harvest this additional graft.

It is desirable to be able to estimate the impact of harvesting a band of quadricipital tendon on the graft's total diameter in order to ensure a sufficient size after supplementation. The objective of this descriptive cadaveric study is therefore to identify the minimum diameter threshold for a $4 \mathrm{~S}$ graft to benefit from the supplementation of a partial thickness quadriceps tendon with a $6 \mathrm{~mm}$ width, in order to obtain a final $4 S+Q$ graft diameter of $8.5 \mathrm{~mm}$ or more.

\section{Material And Methods \\ 2.1. Ethics}

This descriptive cadaveric study was elaborated within the context of a larger project aiming to create a decisional algorithm focused on the different options meant to increase the diameter of $4 \mathrm{~S}$ grafts. The instruments, the evaluators and the specimens used are the same as another study encompassed in this larger project [31]. The protocol was approved by the "Comité d'éthique de la recherche du CIUSSS de l'Estrie-CHUS (Centre intégré universitaire de santé et de services sociaux de l'Estrie - Centre hospitalier universitaire de Sherbrooke).

\subsection{Sample Size}

Each usable cadaver, having previously been consented as a donor to science between January and March 2019, was prepared according to the usual technique for fresh corpse preservation, without embalming, by the technicians of the Medical Faculty's Anatomy Laboratory. A total of 34 cadaveric knees were dissected by one of the orthopedic surgery senior residents in order to harvest the semitendinosus, gracilis and quadriceps tendons while adhering to the usual surgical techniques. Of those 34, 33 samples were deemed usable in our study due to their quality, the absence of structural damage and the absence of previous surgeries on those structures. The age and sex of the cadavers from which these samples were harvested have been tabulated (Table 1).

\subsection{Sample preparation}


Harvesting of every tendon used was done by the same senior resident by using the instruments and surgical techniques typically employed in our center.

An oblique anteromedial incision is made near the insertion of the pes anserinus to the proximal tibia. Subcutaneous adipose tissues are dissected until the sartorius is seen, then incised longitudinally along the axis of its fibers. The gracilis tendon is then isolated and freed from its adherences before being harvested with the tendon harvester for cruciate ligament reconstruction (Conmed Linvatec, Aurora, Ohio). These steps are the same when harvesting the semitendinosus tendon. The remaining muscular fibers are cleaned from the tendons and the two tendons are freed in a subperiosteal manner from their tibial insertion, then set aside for ulterior measures.

Harvesting of the quadriceps tendon band is done through a midline longitudinal incision reaching to the proximal pole of the patella. The subcutaneous adipose tissues are dissected until the quadriceps fascia is seen, then incised along the axis of its fibers with a $6 \mathrm{~mm}$ width in the central part of the tendon. The tendon band is then released from the patella with a depth of about $5 \mathrm{~mm}$ (thickness of the rectus femoris tendon) and this plane is dissected up proximally before being cut to a length of $9 \mathrm{~cm}$. Each group of tendons from the same knee was identified with a code, then frozen until the day of the measurements.

\subsection{Measurements}

At the time of measuring, each group of tendons had been unfrozen at room temperature and kept humid with surgical sponges soaked with normal saline between each step. The $4 \mathrm{~S}$ configuration was then prepared for each group of tendons folded on a PDS suture and the diameter measures were taken using ACL diameter measuring tubes (Conmed Linvatec, Aurora, Ohio), varying from 6,5 to $11,0 \mathrm{~mm}$ in diameter in intervals of $0,5 \mathrm{~mm}$. The graft length was measured with a millimeter graduated ruler. The quadriceps tendon bands were then sutured at the center of the $4 S$ grafts in order to produce grafts in a $4 S+Q$ conformation (figure 1), which were also measured with the Conmed measuring tubes. Each measure was done individually by three evaluators and compiled by a research assistant. Each evaluator also reevaluated 10 grafts, randomly assigned by the research coordinator, in order to establish intraobserver reliability. It is worth noting that the repeated measures were done in a blinded manner. Further analysis of the impact of the augmentation technique were performed using the median value obtained from the three evaluators, for each sample.

\subsection{Statistical calculations}

Statistical calculations and analyses were done by a statistician with SPSS (v23.0.0 from IBM). Descriptive statistics were used for the calculation of means, medians, proportions and confidence intervals.

Inter and intraobserver reliability of graft diameter measures was evaluated with the help of Kendall's coefficient of concordance, which allows evaluation of the concordance of discrete ordinal measures. 


\section{Results}

The demographic characteristics of the studied cadavers can be found in Table 1.

Intraobserver reliability, calculated for $4 S+Q$ grafts, and interobserver reliability, calculated for all the measures in all configurations, are both excellent, with concordances of $0,976(p=0,002)$ and 0,959 $(p<0,001)$ respectively.

The diameter measures used in the results for each sample constitute the median of the three evaluators. Within our population, $69,7 \%$ of grafts had a diameter inferior to $8,5 \mathrm{~mm}$ with a $4 \mathrm{~S}$ configuration (Table 2 ), whereas that ratio fell to $12,1 \%$ after supplementation with a $6 \mathrm{~mm}$ band of rectus femoris tendon (Table 2).

Supplementation with a quadricipital tendon band saw an average increase of $1,49[1,03-1,95]$ in diameter for grafts in $4 \mathrm{~S}$ conformation (Table 3 ). After augmentation, $82,6 \%$ of grafts with a diameter of $7,0 \mathrm{~mm}$ to $8,0 \mathrm{~mm}$ reached the target of $8,5 \mathrm{~mm}$, in comparison with $92,9 \%$ of those with a diameter of $7,5 \mathrm{~mm}$ to $8,0 \mathrm{~mm}$.

\section{Discussion}

The results of our descriptive study indicate a significant increase of the diameter of a 4S graft when supplemented with a quadricipital tendon band. Starting a few years ago, the principal author of this document uses this $4 S+Q$ supplementation technique as a backup option when the $4 S$ graft diameter is insufficient and its length does not allow to triple de hamstring tendons in a $6 \mathrm{~S}$ configuration while using the same tibial fixation. Being part of a larger project aimed at creating a decisional algorithm for graft selection according to diameter and length, this study focuses on better establishing the boundaries and criteria for the use of this type of supplementation. It states that $92,86 \%$ of grafts with a $7,5 \mathrm{~mm}$ or more diameter that did not reach the target of $8,5 \mathrm{~mm}$ in diameter with a $4 \mathrm{~S}$ conformation did so with a $4 \mathrm{~S}+\mathrm{Q}$ conformation with the advantage of maintaining the full length of the doubled hamstring graft.

Other techniques are described in these circumstances too. The other main source of supplementation described is allograft, which presents a higher failure rate than autografts, especially in younger patients[17][18][19]. 6S grafts are a good option if length is satisfactory. According to a study done in our center earlier this year[31], this method would allow an average increase in graft diameter of $1,35 \mathrm{~mm}$ and $95,8 \%$ of grafts measuring $7,5 \mathrm{~mm}$ in diameter or more would therefore reach $8,5 \mathrm{~mm}$. The prerequisite for this technique, however, is that the semitendinosus tendon harvested must measure more than $270 \mathrm{~mm}$ in order to have a minimal length of $90 \mathrm{~mm}$ after preparation, which consists in optimal length, in our experience, for a satisfactory reparation with a tibial interference screw and femoral cortical suspension[32]. A 6S graft configuration or a quadrupled semi-tendinosus can also be used despite a length of less than 90 millimeters, but those options necessitate a tibial suspensory fixation, which entails altering the operating plan and having more fixation options on site. 
Certain limitations are intrinsically linked with the study design employed. Among others, a study based on cadavers can diminish the clinical applicability of its results. This potential bias, as well as the fact that our studied population is much older than the usual ACL reconstruction population, is lessened by comparing the average diameter increase between two configurations rather than the diameter as an absolute number. Moreover, we took care to use recent cadaveric samples, kept fresh and frozen only a short time before harvesting. We also slowly warmed the tendons at room temperature before any manipulation and kept them constantly hydrated between measures using surgical sponges soaked with a saline solution. The total number of samples $(n=33)$ directly limits the numbers per group and might therefore influence the external validity of the experiment. However, that three evaluators performed each measure independently and with excellent inter and intraobserver reliability contributes in countering this effect on external validity.

Several questions, such as the complications associated with the technique as well as the real clinical benefit, are beyond the scope of this project. We realize that adding a second harvesting site adds potential complications. Based on our experience, the two main potential complications following the harvest of a quadriceps tendon band - namely some pain and the post-operative strength of the extensor mechanism[33] - do not seem to be major stakes in the recuperation of patients benefiting from this supplementation. Existing literature demonstrates significantly less anterior knee pain [34][35][23][28][36] and less kneeling pain[37][34][23][28] after harvesting quadricipital tendons when compared with patellar tendon, even when it is harvested with the patellar bone and in its entire thickness. Though it remains to be demonstrated in a subsequent study, we believe that with a quadricipital tendon harvesting technique of partial thickness only, of reduced width and without any bone block, these complications are even rarer. Also, new minimally invasive harvesting techniques could further reduce these potential complications[38].

This descriptive study backs the use of quadricipital tendon supplementation described by Wilson et al. [30] and constitutes only the second study on the matter. In this sense, it contributes in establishing the foundations necessary to the elaboration of further clinical projects.

The diameter obtained with a $6 \mathrm{~mm}$ band of rectus femoris did not reach $8.5 \mathrm{~mm}$ or more for all $4 \mathrm{~S}$ grafts. Therefore, future work could evaluate the use of rectus femoris bands of greater widths, the $6 \mathrm{~S}$ or even the $6 S+Q$ configurations for the smaller sizes of $4 S$ grafts.

Greater characterization of side effects related to this technique is also necessary before any wide-range application.

We must also not underestimate the risks associated with too great an increase of the graft diameter. In fact, an oversized graft in a tight femoral notch could also increase the risk of failure from repeated impingements on the roof of this notch during extension. Fu et Al. pronounce this same warning when they propose to estimate with MRI the diameter of the native ACL and attempt to reproduce it[39]. In this context, it will be interesting to continue to evaluate increases in graft diameter according to different 
configurations or supplementations in order to be able to predictably choose from a complete quiver of options to obtain the right graft size for the right patient.

\section{Conclusion}

In conclusion, a minimum graft diameter of $8.5 \mathrm{~mm}$ is reached with initial $4 \mathrm{~S}$ graft of $7.5 \mathrm{~mm}$ or more in $92.6 \%$ in this sample. Supplementing doubled hamstring graft (4S) with quadricipital tendon in ACL reconstruction is an option to be added to our arsenal, which increases the graft diameter by an average of 1,49 millimeters. More descriptive, biomechanical and clinical studies are necessary in order to establish with greater certainty where exactly this option resides within a future decisional algorithm based around graft diameter and length.

\section{Declarations}

\section{Ethics approval and consent to participate:}

The study protocol was approved by the "Comité d'éthique de la recherche du CIUSSS de l'Estrie-CHUS (Centre intégré universitaire de santé et de services sociaux de l'Estrie - Centre hospitalier universitaire de Sherbrooke). Final approval was obtained on march 13th, 2019 with the study number 2019-3057. Consent for cadavers use was obtained by the director of the Laboratoire d'anatomie, Centre de simulation PRACCISS de la faculté de médecine et des sciences de la sante de l'Université de Sherbrooke.

\section{Consent for publication :}

Not applicable

\section{Availability of data and materials:}

The datasets generated and analysed during the current study are not publicly available but are available from the corresponding author on reasonable request.

\section{Competing interests:}

YBG, KAL and $\mathrm{KL}$ have no competing interest to declare regarding this research project.

SB, FB and FV received unrestricted grants for research and training from Depuy-Synthes, Wright medical and Zimmer-Biomet. Surgical material used for harvesting the tendons was provided by Conmed.

\section{Funding:}

The funds were granted by the surgery department of the CIUSSS de l'Estrie-CHUS and the FREOS (Fondation de Recherche et d'Enseignement en Orthopédie de Sherbrooke).

\section{Authors' contributions:}


YBG contributed to data collection, analyses, interpretation and was a major contributor in writing the manuscript.

KAL, SB, FB and FV contributed to protocol conception, data collection, analyses, interpretation and manuscript writing.

$\mathrm{KL}$ contributed to conception, statistical analyses, interpretation and manuscript revision.

All authors read and approved the final manuscript.

\section{Acknowledgements:}

Special thanks to Claudia Beaulieu, Sonia Paquette and Denis Bisson, technicians in the anatomy laboratory, who helped us greatly with the preservation and preparation of samples. We would also like to thank Catherine Raynaud, who helped with data collection and Sean David Gagnon who helped for the English translation.

\section{References}

1. Magnussen RA, Lawrence JTR, West RL, Toth AP, Taylor DC, Garrett WE. Graft size and patient age are predictors of early revision after anterior cruciate ligament reconstruction with hamstring autograft. Arthrosc - J Arthrosc Relat Surg. 2012;28:526-31. https://doi.org/10.1016/j.arthro.2011.11.024.

2. Shelbourne KD, Gray T, Haro M. Incidence of subsequent injury to either knee within 5 years after anterior cruciate ligament reconstruction with patellar tendon autograft. Am J Sports Med. 2009;37:246-51. https://doi.org/10.1177/0363546508325665.

3. Conte EJ, Hyatt AE, Gatt CJ, Dhawan A. Systematic Review Hamstring Autograft Size Can Be Predicted and Is a Potential Risk Factor for Anterior Cruciate Ligament Reconstruction Failure. Arthrosc J Arthrosc Relat Surg. 2014;30:882-90. https://doi.org/10.1016/j.arthro.2014.03.028.

4. Mariscalco MW, Flanigan DC, Mitchell J, Pedroza AD, Jones MH, Andrish JT, et al. The influence of hamstring autograft size on patient-reported outcomes and risk of revision after anterior cruciate ligament reconstruction: A multicenter orthopaedic outcomes network (MOON) cohort study. Arthrosc - J Arthrosc Relat Surg. 2013;29:1948-53. https://doi.org/10.1016/j.arthro.2013.08.025.

5. Borchers JR, Pedroza A, Kaeding C. Activity level and graft type as risk factors for anterior cruciate ligament graft failure: A case-control study. Am J Sports Med. 2009;37:2362-7. https://doi.org/10.1177/0363546509340633.

6. Salmon L, App B, Sci V, Russell T, Musgrove MBBS, Pinczewski L, et al. Incidence and Risk Factors for Graft Rupture and Contralateral Rupture After Anterior Cruciate Ligament Reconstruction 2005. https://doi.org/10.1016/j.arthro.2005.04.110.

7. Mohtadi N, Chan D, Barber R, Paolucci EO. Reruptures, reinjuries, and revisions at a minimum 2-year follow-up: A randomized clinical trial comparing 3 graft types for ACL reconstruction. Clin J Sport 
Med. 2016;26:96-107. https://doi.org/10.1097/JSM.0000000000000209.

8. Marchand JB, Ruiz N, Coupry A, Bowen M, Robert H. Do graft diameter or patient age influence the results of ACL reconstruction? Knee Surgery. Sport Traumatol Arthrosc. 2016;24:2998-3004. https://doi.org/10.1007/s00167-015-3608-6.

9. Charalambous $\mathrm{CP}$, Kwaees TA. Anatomical considerations in hamstring tendon harvesting for anterior cruciate ligament reconstruction. Muscles Ligaments Tendons J. 2012;2:253-7.

10. Hamner DL, Brown CH, Steiner ME, Hecker AT, Hayes WC. Hamstring tendon grafts for reconstruction of the anterior cruciate ligament: Biomechanical evaluation of the use of multiple strands and tensioning techniques. J Bone Jt Surg - Ser A. 1999;81:549-57. https://doi.org/10.2106/00004623$199904000-00013$.

11. Boniello MR, Schwingler PM, Bonner JM, Robinson SP, Cotter A, Bonner KF. Impact of Hamstring Graft Diameter on Tendon Strength: A Biomechanical Study. Arthrosc - J Arthrosc Relat Surg. 2015;31:1084-90. https://doi.org/10.1016/j.arthro.2014.12.023.

12. Snaebjörnsson T, Hamrin Senorski E, Ayeni OR, Alentorn-Geli E, Krupic F, Norberg F, et al. Graft Diameter as a Predictor for Revision Anterior Cruciate Ligament Reconstruction and KOOS and EQ5D Values A Cohort Study From the Swedish National Knee Ligament Register Based on 2240 Patients Thorkell. Am J Sports Med. 2017;45:2092-7. https://doi.org/10.1177/0363546517704177.

13. Spragg L, Chen J, Mirzayan R, Love R, Maletis G. The effect of autologous hamstring graft diameter on the likelihood for revision of anterior cruciate ligament reconstruction. Am J Sports Med. 2016;44:1475-81. https://doi.org/10.1177/0363546516634011.

14. Park SY, Oh H, Park S, Lee JH, Lee SH, Yoon KH. Factors predicting hamstring tendon autograft diameters and resulting failure rates after anterior cruciate ligament reconstruction. Knee Surgery Sport Traumatol Arthrosc. 2013;21:1111-8. https://doi.org/10.1007/s00167-012-2085-4.

15. Krishna L, Panjwani T, Ren Mok Y, Keng Lin Wong F, Singh A, Jie Toh S. Use of the 5-Strand Hamstring Autograft Technique in Increasing Graft Size in Anterior Cruciate Ligament Reconstruction n.d. https://doi.org/10.1016/j.arthro.2018.03.026.

16. Brown CH. Editorial Commentary: How to Increase Hamstring Tendon Graft Size for Anterior Cruciate Ligament Reconstruction 2018. https://doi.org/10.1016/j.arthro.2018.06.014.

17. Wang H-D, Gao S-J, Zhang Y-Z. Comparison of Clinical Outcomes After Anterior Cruciate Ligament Reconstruction Using a Hybrid Graft Versus a Hamstring Autograft n.d. https://doi.org/10.1016/j.arthro.2017.11.020.

18. Perkins CA, Busch MT, Christino M, Herzog MM, Willimon SC. Allograft Augmentation of Hamstring Anterior Cruciate Ligament Autografts Is Associated With Increased Graft Failure in Children and Adolescents. Am J Sports Med. 2019;47:1576-82. https://doi.org/10.1177/0363546519849607.

19. Pennock AT, Ho B, Parvanta K, Edmonds EW, Chambers HG, Roocroft JH, et al. Does Allograft Augmentation of Small-Diameter Hamstring Autograft ACL Grafts Reduce the Incidence of Graft Retear? Am J Sports Med. 2017;45:334-8. https://doi.org/10.1177/0363546516677545. 
20. Hughes JD, Vaswani R, Gibbs CM, Tisherman RT, Musahl V. Anterior Cruciate Ligament Reconstruction With a Partial-Thickness Quadriceps Tendon Graft Secured With a Continuous-Loop Fixation Device. Arthrosc Tech. 2020;9:e603-9. https://doi.org/10.1016/j.eats.2020.01.016.

21. Kanakamedala AC, de SAD, Obioha, Arakgi OA, Schmidt ME, Lesniak PB. BP, et al. No difference between full thickness and partial thickness quadriceps tendon autografts in anterior cruciate ligament reconstruction: a systematic review. Knee Surgery Sport Traumatol Arthrosc. 2019;27:10516. https://doi.org/10.1007/s00167-018-5042-z.

22. Stäubli HU, Schatzmann L, Brunner P, Rincón L, Nolte LP. Mechanical tensile properties of the quadriceps tendon and patellar ligament in young adults. Am J Sports Med. 1999;27:27-34. https://doi.org/10.1177/03635465990270011301.

23. Cavaignac E, Coulin B, Tscholl P, Nik N, Fatmy M, Duthon V, et al. Is Quadriceps Tendon Autograft a Better Choice Than Hamstring Autograft for Anterior Cruciate Ligament Reconstruction? A Comparative Study With a Mean Follow-up of 3.6 Years n.d. https://doi.org/10.1177/0363546516688665.

24. Lee S, Seong SC, Jo H, Park YK, Lee MC. Outcome of anterior cruciate ligament reconstruction using quadriceps tendon autograft. Arthrosc - J Arthrosc Relat Surg. 2004;20:795-802. https://doi.org/10.1016/S0749-8063(04)00594-8.

25. Rabuck SJ, MusahI V, Fu FH, West RV. Anatomic Anterior Cruciate Ligament Reconstruction with Quadriceps Tendon Autograft. Clin Sports Med. 2013;32:155-64. https://doi.org/10.1016/j.csm.2012.08.014.

26. DeAngelis JP, Fulkerson JP. Quadriceps Tendon-A Reliable Alternative for Reconstruction of the Anterior Cruciate Ligament. Clin Sports Med. 2007;26:587-96. https://doi.org/10.1016/j.csm.2007.06.005.

27. Diermeier T, Tisherman R, Hughes J, Tulman M, Baum Coffey E, Fink C, et al. Quadriceps tendon anterior cruciate ligament reconstruction. Knee Surgery, Sport Traumatol Arthrosc 2020. https://doi.org/10.1007/s00167-020-05902-z.

28. Slone HS, Romine SE, Premkumar A, Xerogeanes JW. Quadriceps Tendon Autograft for Anterior Cruciate Ligament Reconstruction: A Comprehensive Review of Current Literature and Systematic Review of Clinical Results. Vol. 31: W.B. Saunders; 2015. https://doi.org/10.1016/j.arthro.2014.11.010.

29. Hurley ET, Calvo-Gurry M, Withers D, Farrington SK, Moran R, Moran CJ. Quadriceps Tendon Autograft in Anterior Cruciate Ligament Reconstruction: A Systematic Review. Arthrosc - J Arthrosc Relat Surg. 2018;34:1690-8. https://doi.org/10.1016/j.arthro.2018.01.046.

30. Wilson WK, Morris R, Coskey A, Smith B, Gugala Z. Quadriceps augmentation of undersized hamstrings during ACL reconstruction. Knee. 2019;26:73-8. https://doi.org/10.1016/j.knee.2018.11.012.

31. Vézina F, Balg F, Leang KA, Bourgeault-Gagnon Y, Lebel K, Bédard S. Prédiction de l'augmentation de diamètre d'un greffon d'ischiojambiers en le tripplant pendant une reconstruction de LCA. En Process 
Soumission n.d.

32. Lee RJ, Ganley TJ. The 5-strand hamstring graft in anterior cruciate ligament reconstruction. Arthrosc Tech. 2014;3:e627-31. https://doi.org/10.1016/j.eats.2014.07.002.

33. Iriuchishima T, Ryu K, Okano T, Suruga M, Aizawa S, Fu FH. The evaluation of muscle recovery after anatomical single-bundle ACL reconstruction using a quadriceps autograft. Knee Surgery Sport Traumatol Arthrosc. 2017;25:1449-53. https://doi.org/10.1007/s00167-016-4124-z.

34. Gorschewsky O, Klakow A, Pütz A, Mahn H, Neumann W. Clinical comparison of the Autologous Quadriceps Tendon (BQT) and the Autologous Patella Tendon (BPTB) for the reconstruction of the Anterior Cruciate Ligament. Knee Surgery. Sport Traumatol Arthrosc. 2007;15:1284-92. https://doi.org/10.1007/s00167-007-0371-3.

35. Han HS, Seong SC, Lee S, Lee MC. Anterior cruciate ligament reconstruction: Quadriceps versus patellar autograft. Clin Orthop Relat Res. 2008;466:198-204. https://doi.org/10.1007/s11999-0070015-4.

36. Lund $B$, Nielsen T, Faun $\varnothing$, Christiansen SE, Lind M. Is quadriceps tendon a better graft choice than patellar tendon? A prospective randomized study. Arthrosc - J Arthrosc Relat Surg. 2014;30:593-8. https://doi.org/10.1016/j.arthro.2014.01.012.

37. Kim SJ, Kumar P, Oh KS. Anterior Cruciate Ligament Reconstruction: Autogenous Quadriceps Tendon-Bone Compared With Bone-Patellar Tendon-Bone Grafts at 2-Year Follow-up. Arthrosc - J Arthrosc Relat Surg. 2009;25:137-44. https://doi.org/10.1016/j.arthro.2008.09.014.

38. Slone HS, Xerogeanes JW. Anterior Cruciate Ligament Reconstruction with Quadriceps Tendon Autograft: A Minimally Invasive Harvest Technique. JBJS Essent Surg Tech. 2014;4:e16. https://doi.org/10.2106/JBJS.ST.N.00012.

39. Offerhaus C, Albers M, Nagai K, Arner JW, Höher J, Musahl V, et al. Individualized Anterior Cruciate Ligament Graft Matching: In Vivo Comparison of Cross-sectional Areas of Hamstring, Patellar, and Quadriceps Tendon Grafts and ACL Insertion Area. Am J Sports Med. 2018;46:2646-52. https://doi.org/10.1177/0363546518786032.

\section{Tables}

Table 1

Demographic characteristics

\begin{tabular}{|ll|}
\hline Number of samples & $\mathbf{1 7}$ cadavers (33 samples) \\
\hline Average age & $76.2 \pm 13.6$ years \\
\hline BMl & $22.6 \pm 4 \mathrm{~kg} / \mathrm{m}^{2}$ \\
\hline Sex & $52.9 \% \mathrm{men}$ \\
\hline
\end{tabular}


Table 2

$4 \mathrm{~S}$ and $4 \mathrm{~S}+\mathrm{Q}$ graft diameters

\begin{tabular}{|lll|}
\hline Diameter (mm) & $\mathbf{n ~ 4 S ~ ( \% ) ~}$ & $\mathbf{n ~ 4 S + Q ~ ( \% ) ~}$ \\
\hline 7.0 & $9(27.3 \%)$ & $0(0 \%)$ \\
\hline 7.5 & $6(18.2 \%)$ & $0(0 \%)$ \\
\hline 8.0 & $8(24.2 \%)$ & $4(12.1 \%)$ \\
\hline 9.0 & $9(27.3 \%)$ & $4(12.1 \%)$ \\
\hline 9.5 & $1(3.0 \%)$ & $8(24.2 \%)$ \\
\hline 10.0 & $0(0 \%)$ & $8(24.2 \%)$ \\
\hline 10.5 & $0(0 \%)$ & $7(21.2 \%)$ \\
\hline 11.0 & $0(0 \%)$ & $1(3.0 \%)$ \\
\hline
\end{tabular}

Due to technical limitations, table 1 is only available as a download in the Supplemental Files section.

\section{Figures}

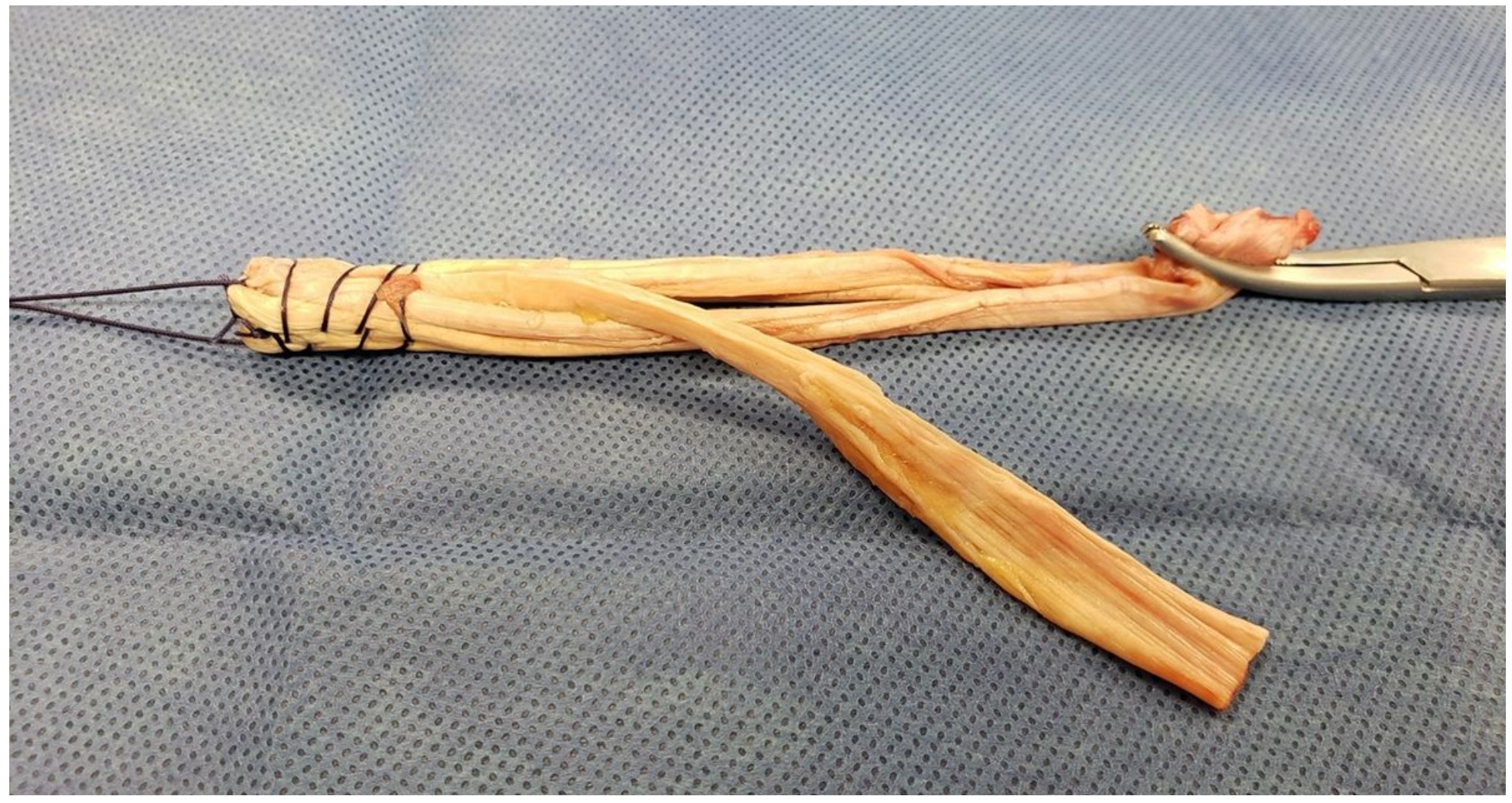

Figure 1 
$4 S+Q$ graft configuration

Black arrowhead : quadricipital band. White arrow : Four bundle hamstring graft

\section{Supplementary Files}

This is a list of supplementary files associated with this preprint. Click to download.

- Table3.jpg 